Proceedings

\title{
Online Monitoring of Composites with a Miniaturized Flexible Combined Dielectric and Temperature Sensor ${ }^{+}$
}

\author{
Martina Hübner * and Walter Lang \\ Institute for Microsensors, Actuators and-Systems (IMSAS), University of Bremen, 28359 Bremen, Germany; \\ wlang@imsas.uni-bremen.de \\ * Correspondence: mhuebner@imsas.uni-bremen.de; Tel.: +49-421-218-62618 \\ + Presented at the Eurosensors 2017 Conference, Paris, France, 3-6 September 2017. \\ Published: 11 August 2017
}

\begin{abstract}
We present a foil based miniaturized impedance sensor combined with a temperature sensitive structure to be integrated in Carbon-Fiber-Reinforced-Polymer (CFRP). Commercially available sensors are too big and they weaken the CFRP. In contrast the influence of our miniaturized flexible sensor can be neglected due to its size ( $5 \mu \mathrm{m}$ thick); it is in the range of the fibers' diameter. The sensor can remain in the produced part without disruption and even be used for structural health monitoring. Our sensor will enable automated control of the curing process and improve the fabrication. This is the first time impedance and temperature sensing is combined in such a small size.
\end{abstract}

Keywords: interdigital structure; cure monitoring; impedance spectroscopy; material integration

\section{Introduction}

Monitoring the production of composites and their lifetime is important not only because it allows improving the fabrication processes, but also because new applications for composites can be developed by monitoring curing and aging. Dielectric analysis with interdigital sensors is a standard method suitable for in-situ measurement [1]. Besides the changes in the dielectric properties during curing, temperature is an important factor, which has to be measured. The temperature in the composite during fabrication can differ from the specified curing temperature due to chemical reactions occurring in composite processing. The actual temperature in the material can influence the final product quality. Our sensor can be used for automated temperature control to monitor the curing process and to improve the quality.

In this paper, we present a miniaturized flexible multifunctional sensor as shown in Figure 1. It is able to measure temperature and dielectric parameter at the same time. In addition the resistive structure, which is used for the temperature monitoring, is designed as a shielding for the interdigital structure [2]. This improves the quality of the measured impedance spectra.

\section{Materials and Methods}

In Figure 1a our flexible miniaturized interdigital sensor is shown in comparison to a pencil tip. Figure $1 \mathrm{~b}$ shows a micrograph of the sensor. The sensor consists of an interdigital structure with 150 fingers with equal width and spacing of $10 \mu \mathrm{m}$, see Figure 2, which is in the same range as the diameter of carbon fibers. The length of the finger of the interdigital structure is $6 \mathrm{~mm}$. In addition to the interdigital structure, a resistive structure is built on the same substrate surrounding that. 
The total length of the resistive structure is $13.95 \mathrm{~mm}$ and the width is $40 \mu \mathrm{m}$. Since the structure is thermoresistive, it can be used to measure temperature directly inside the material.

Processing the sensor starts with spin coating Polyimide (U-Varnish S, UBE) on a silicon wafer. The thickness after curing is about $5 \mu \mathrm{m}$. Polyimide is chosen as a substrate because it can be fabricated in the desired thickness, it is highly flexible and it withstands the high temperatures (up to $200{ }^{\circ} \mathrm{C}$ ) during the fabrication process. Afterward, $300 \mathrm{~nm}$ gold is sputtered and wet chemical structured. The last fabrication step is dry etching of the polyimide substrate to separate the sensors. Between the fingers, holes are etched in the polyimide to allow the resin flow through the sensor. The holes have a size of about $10 \mu \mathrm{m} \times 10 \mu \mathrm{m}$ (see Figure 1b).

To calibrate the resistive behavior with respect to the temperature, the sensor is placed in an oven and the temperature is varied from $40{ }^{\circ} \mathrm{C}$ to $150{ }^{\circ} \mathrm{C}$. In addition the impedance of the sensor in air is measured. After characterization the sensor is placed in a mold with RTM6 resin (from Hexel, commonly used in aerospace industry) and cured at a constant temperature of $120^{\circ} \mathrm{C}$ for eight hours.

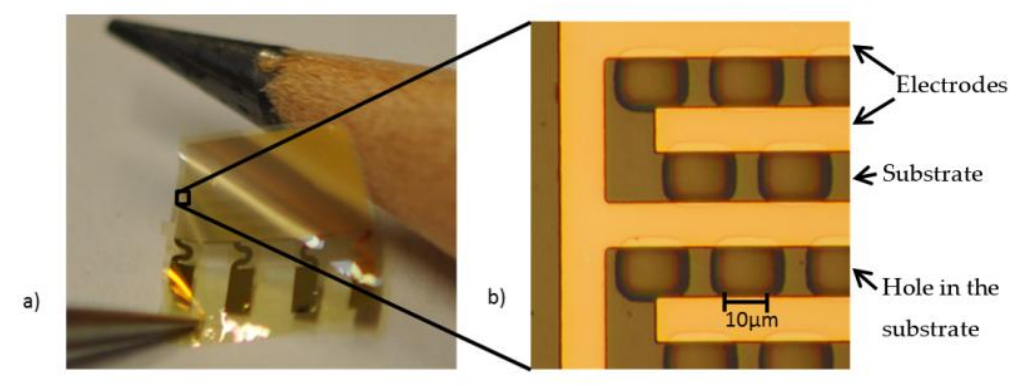

Figure 1. (a) Bended flexible sensor with sensing area $6.2 \mathrm{~mm} \times 4 \mathrm{~mm}$; (b) Micrograph of a part of the sensor.

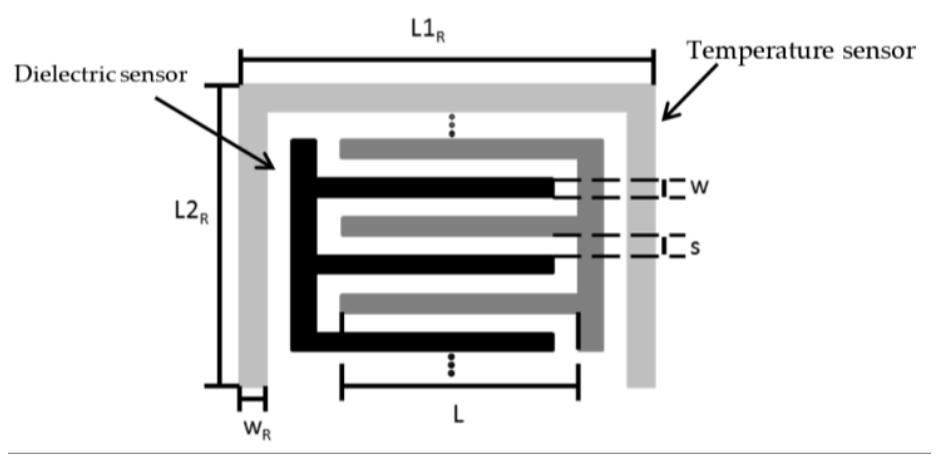

Figure 2. Schematic of the sensor (top view). The interdigital structure in the middle consists of $\mathrm{N}=150$ electrodes with width $\mathrm{w}=10 \mu \mathrm{m}$ and spacing $\mathrm{s}=10 \mu \mathrm{m}$. The length is $\mathrm{L}=6 \mathrm{~mm}$. The resistive structure has a total length of $L_{R}=2 \times L 2_{R}+L 1_{R}=2 \times 3.89 \mathrm{~mm}+6.17 \mathrm{~mm}=13.95 \mathrm{~mm}$ and a width of $40 \mu \mathrm{m}$.

\section{Results}

In Figure 3a the resistance of the gold thin film structure is shown in dependence of the temperature. The temperature to resistance characteristics is fully linear in the tested temperature range. The resistance increases about $0.12 \Omega$ per degree Celsius. Therefore the resistive structure can be used to measure the temperature inside the material. The impedance stays constant during the temperature variations.

In Figure $3 b$ the temperature measured with the resistive structure is shown compared to the temperature of a commercial thermocouple. The sensor is placed in the mold and heated up to $120{ }^{\circ} \mathrm{C}$. Then the oven is opened to apply the RTM6. Since the RTM6 is only preheated to $40{ }^{\circ} \mathrm{C}$ the temperature drops for a short time. Afterwards temperature of the commercial thermocouple, which 
is directly placed underneath the mold, stays constant at $121^{\circ} \mathrm{C}$. The temperature measured with the resistive structure in the RTM6 is slightly higher and drops after $5 \mathrm{~h}$ to $120^{\circ} \mathrm{C}$.
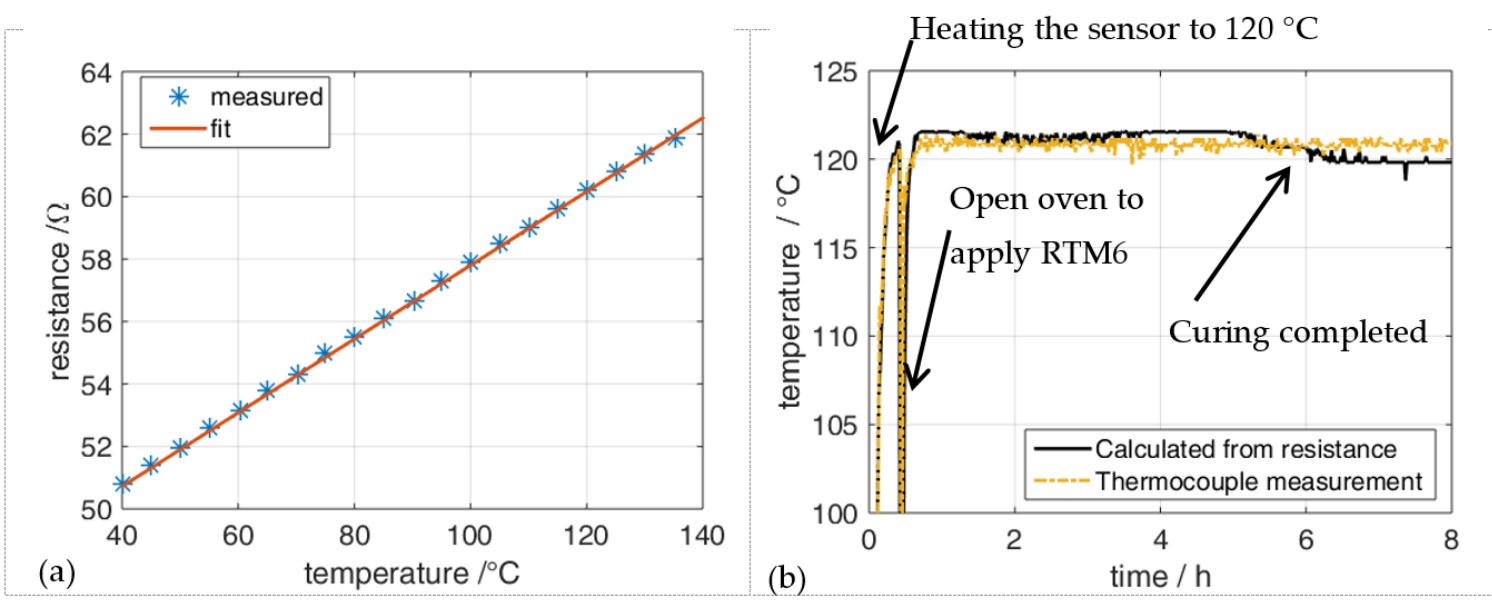

Figure 3. (a) Measured temperature characteristics of the resistive structure; (b) Temperature in the resin measured with the resistive structure and externally measured temperature during the curing of the RTM6 resin.

In Figure 4 the absolute value of the impedance during curing is shown over time for selected frequencies. The curing process can be directly correlated to the impedance value. During curing the viscosity of the material increase. The movement of the free charges inside the material decreases and therefore the resistance of the material increases. This can be correlated to the increase of the absolute value of the impedance [3]. After five hours the absolute value of the impedance stays constant. This indicates that the curing process of the RMT6 is completed.

Comparing the temperature profile and the impedance measurement inside the RMT6, the dropping temperature after five hours can be correlated to the completed curing process. The curing process of RMT6 is an exothermic reaction [4]. Therefore the resistive structure inside the RTM6 measures the additional heat of the reaction. When the reaction is finished the temperature drops. This demonstrates that monitoring of the temperature directly inside the material is very important: since the externally measured temperature stays constant, the internal temperature drops after sufficient curing.

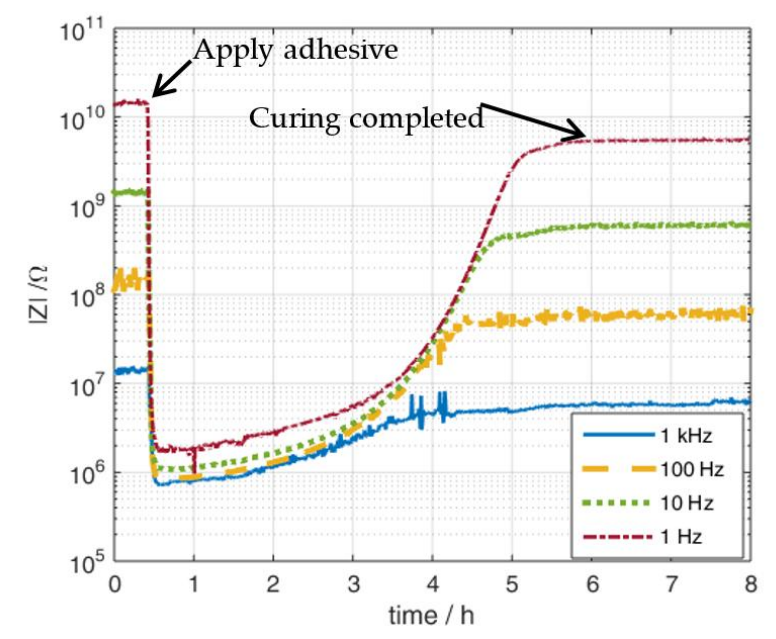

Figure 4. Absolute impedance over time for selected frequencies during curing of RTM6 (Hexel) resin. In a first step the RTM6 get less viscous due to the higher temperature $\left(120^{\circ} \mathrm{C}\right)$ which can be seen from the quickly decreasing impedance. Then the curing process starts and the impedance rise. After $5 \mathrm{~h}$ curing stops and no changes in the impedance can be seen. 


\section{Discussion and Conclusions}

We used a combined temperature and impedance sensor, which can be integrated in the material, to monitor the curing of RTM6. We demonstrated that it is important to measure the temperature inside the material, because the temperature deviate from the externally measured temperature. In contrast to relatively big standard sensors (several hundred microns), our sensor has a small dimension. This makes it suitable to remain in the material for lifetime monitoring. Our sensor realizes impedance and temperature measurement at the same time enabling the automated control of the process without harming the fabric.

In future work mechanical tests have to be performed to demonstrate that the sensor does not harm the material. In addition a commercial temperature sensor should also be located inside the material to verify the measured temperature profile inside the material.

Acknowledgments: The work is funded by the German Research Foundation (DFG) within the project "Kammsensor: Integration flexibler kapazitiver Sensoren in Polymere zur Überwachung von Polymerisationsund Degradationsprozessen" (LA 1471/17-1).

Conflicts of Interest: The authors declare no conflict of interest. The founding sponsors had no role in the design of the study; in the collection, analyses, or interpretation of data; in the writing of the manuscript, and in the decision to publish the results.

\section{References}

1. Kahali Moghaddam, M.; Breede, A.; Chaloupka, A.; Bödecker, A.; Habben, C.; Meyer, E.M.; Brauner, C.; Lang, W. Design, fabrication and embedding of microscale interdigital sensors for real-time cure monitoring during composite manufacturing. Sens. Actuators A 2016, 243, 123-133, doi:10.1016/j.sna.2016.03.017.

2. Yang, Y.; Chiesura, G.; Vervust, T.; Degrieck, J.; Vanfleteren, J. Design and Fabrication of a Shielded Interdigital Sensor for Noninvasive In Situ Real-Time Production Monitoring of Polymers. J. Polym. Sci. B 2016, 2028-2037, doi:10.1002/polb.24101.

3. Mijovic, J.; Yee, C.F.W. Use of Complex Impedance to Monitor the Progress of Reactions in Epoxy/Amine Model Systems. Macromolecules 1994, 27, 7287-7293, doi:10.1021/ma00103a009.

4. Causse, N.; Benchimol, S.; Martineau, L.; Carponcin, D.; Lonjon, A.; Fogel, M.; Dandurand, J.; Dantras, E.; Lacabanne, C. Polymerization study and rheological behavior of a RTM6 epoxy resin system during preprocessing step. J. Therm. Anal. Calorim. 2015, 119, 329-336, doi:10.1007/s10973-014-4147-y.

(C) 2017 by the authors. Licensee MDPI, Basel, Switzerland. This article is an open access article distributed under the terms and conditions of the Creative Commons Attribution (CC BY) license (http://creativecommons.org/licenses/by/4.0/). 